\title{
Pensononowoor
}

2016, vol. 76, 127-136

http://dx.doi.org/10.12657/denbio.076.012

\author{
Marko Stojanović, Matjaž Čater*, Radek Pokorný
}

\section{Responses in young Quercus petraea: coppices and standards under favourable and drought conditions}

Received: 22 February 2016; Accepted: 3 August 2016

\begin{abstract}
Assimilation and photosynthetic efficiency (maximal quantum yield) of young oaks were compared in coppice and standard sessile oak stands of comparable age (100 years) under different light intensity categories: under minimum light $-\mathrm{ISF}<20 \%$, low light $-20 \%<\mathrm{ISF}<25 \%$, medium light $-25 \%<\mathrm{ISF}<30 \%$ and in the open, without mature canopy cover - ISF $>30 \%$ during favourable and drought conditions. Measurements of maximal assimilation rates were performed at a constant temperature of the measurement block $\left(20^{\circ} \mathrm{C}\right)$, a $\mathrm{CO}_{2}$ concentration of $400 \mu \mathrm{mol} / 1$, flow $500 \mu \mathrm{mol} / \mathrm{s}$ and different light intensities: 0 , 50, 250, 600, 1200 and $1800 \mu \mathrm{mol} / \mathrm{m}^{2}$ s during three consecutive growing seasons (2012, 2013 and 2014). In every category at least 8 young naturally regenerated seedlings and sprouts of different coppice stools were measured. The quantum yield in optimal conditions in standards was highest in the category of closed canopy, while in coppices in medium light category. During severe drought in 2013 the drop in efficiency of standards was evident in all categories, while in coppices no differences in efficiency were observed between favourable 2012 and 2013 with expressed drought stress, proving the advantage of young coppices over standards in this particular light category. However, the beneficial effects of restoration coppicing are not guaranteed. It is our belief that in time such advantage might decrease; it would be therefore interesting to compare responses in time and define, when response abilities of both studied systems become equal.
\end{abstract}

Keywords: coppice, standards, comparison, photosynthetic response, quantum yield, light conditions, drought response

Addresses: M. Stojanović, M. Čater, R. Pokorny, Department of Silviculture, Faculty of Forestry and Wood Technology, Mendel University in Brno, Zemědělská 3, 61300 Brno, Czech Republic, e-mail: marko.stojanovic@mendelu.cz

M. Stojanović, R. Pokorny, Global Change Research Institute, Academy of Science of the Czech Republic, Bělidla 4a, 60300 Brno, Czech Republic, e-mail: pokorny.r@czechglobe.cz

M. Čater, Slovenian Forestry Institute, Večna pot 2, 1000 Ljubljana, Slovenia, e-mail: matjaz.cater@ gozdis.si

${ }^{*}$ Corresponding author 


\section{Introduction}

Coppice systems, as one of the oldest known forest-management systems (Honnay et al., 2004) are characterized by a vegetative reproduction, which is different to generative establishment of the stands, also known as standards or high forests (Peterken, 1993). In central Europe, where broadleaved forests have been managed as coppices for centuries, most coppice woods have been transformed into high-forests either by replanting or by reducing the underwood to one or more large trunks (Peterken, 1996; Rackham, 2008). Coppicing was abandoned in the second part of $19^{\text {th }}$ century due to socio-economic changes, leaving large areas of forest developing into aged coppice stands (Buckley, 1992).

Recently, interest in the reintroduction of coppicing to protect endangered species (Vild et al., 2013) and obtain a sustainable source of energy (McKenney et al., 2011) has been steadily increasing in many European regions (Müllerová et al., 2015).

Recently, the conservational aspect and biodiversity (Peterken, 1996) and as a historical landscape element and habitat with high nature conservation value are becoming more popular (Buckley, 1992; Kadavý et al., 2011).

Climate change brings about a new impetus to understanding the consequences of different forest management practices for forest resilience (IPCC, 2001; Millar et al., 2007). It is expected that the abundance of extreme events in Europe, especially in Central and Southern Europe, would increase (Lindner et al., 2010; Milad et al., 2011). Drought has been suggested as the major factor causing tree decline in Europe in the last decades (Allen et al., 2010), so there is a need to encourage forest resilience both for benefit of reliable resource provision and for conservation (Allen et al., 2010). Understanding the benefits and threats of exploiting vegetative regeneration is the first step in assessing, whether promoting this means of reproduction could be used for conservation by increasing forest persistence under future climate conditions (Sjölund \& Jump, 2013).

Sessile oak, known as drought resistant tree species (Leuzinger et al., 2005) developed morphological (curled leaves, leaf loss, deep roots) and physiological (stomatal conductance, osmotic adjustment) strategies to adapt to drought stress (Aranda et al., 1996; Dickson \& Tomlinson, 1996). An intermediate species develops deeper and larger root system and smaller xylem vessels that are less exposed to cavitation, compared to pedunculate oak (Arend et al., 2011). Under drought events, sessile oaks decrease net $\mathrm{CO}_{2}$ assimilation rates and stomatal conductance, although they remain productive under severe drought (Bréda et al., 1993). When drought period is over, oaks re-open the stomata (Zweifel et al., 2009).
Seedlings adapt to drought conditions by higher carbon partitioning to roots - producing more fine-root biomass and decreasing the production of leaves and stem biomass in order to reduce transpiration loss (Thomas \& Gausling, 2000).

Increased drought in the low-latitude range edge of species has been shown to have a negative effect on seedling survival as well as adult growth in Quercus ilex L. (Pérez-Ramos et al., 2010), Fagus sylvatica (Silva et al., 2012) and Phillyrea latifolia (Lloret et al., 2004), further threatening the persistence of such populations under climate change (Jump et al., 2010). Vegetative regeneration presents an alternative regeneration pathway that can be used to maintain existing trees in a forest, facilitating the adaptation of associated species by avoiding substantial changes in species composition, and therefore promoting current forest persistence (Sjölund \& Jump, 2013).

In areas that are more likely to be affected by drought, keeping an overstorey of high forest and promoting a coppice understorey would provide sufficient canopy cover and consequently soil cover to preserve soil humidity. Sprouts from stools are believed to have better competitive abilities than generative seedlings because of their pre-established root system and consequently better water and nutrient availability (Zhu et al., 2012).

Main silvicultural tool is the creation of appropriate light environment in forest stands. The quality and stability of forests is therefore in tight connection with our understanding of tree-response to different light conditions. Assessing differences between standards and coppice would therefore highlight the important benefits and weaknesses of both systems and provide insights into adaptive forest management strategies.

We aimed at comparing performance of 10-yearold sessile oaks (Quercus petraea (Matt.) Liebl.) from the seed origin (standards) with sprouts of the same age growing from the stools in the coppice forest under contrasting light conditions. Response of both groups was compared under various light intensities according to closure of mature canopy (1) and in drought (2). Our aim was to compare same light categories and highlight those, where performance of young seedlings would show most differences. We hypothesised that same light categories in coppices and standards would show no differences in quantum yield and there would be no difference between coppices and standards of the same light category in yield during drought. 


\section{Material and methods}

\section{Site description}

The study was performed in coppice and high sessile oak stands of the same age (100 years). The study sites were located in a mixed Carpineto-Quercetum forest located near Brno in South Moravia, Czech Republic $\left(49^{\circ} 14^{\prime} \mathrm{N}, 16^{\circ} 36^{\prime} \mathrm{E}\right)$. Both sites were $3.1 \mathrm{~km}$ apart. High forest has been managed by the shelterwood system, while the coppice forest plots were established after cutting of an overaged sessile oak coppice forest with different felling intensities (Kadavý et al., 2011).

The area is situated $360 \mathrm{~m}$ above sea level with loess soils of $30-40 \mathrm{~cm}$. The subsoil is an illimerized layer of forest soil on loamy alluvium and granodiorite with an inaccessible ground water table. The long-term mean annual temperature reaches $7.5^{\circ} \mathrm{C}$, while the mean annual precipitation is $550-650 \mathrm{~mm}$ - $360 \mathrm{~mm}$ during the growing season (1980-2010 period). According to the Köppen classification, the climate is moist with mild winters and well distributed precipitation over all seasons (CMHI, 2014). Sessile oak (Quercus petraea) is the predominant tree species in the forest sites.

\section{Light conditions}

On every site, four research plots were established under mature canopy stand ranged from complete canopy closure to open sky conditions assessed by hemispherical photo analysis (Čater et al., 2012).
The proportion of diffuse light compared to the open area conditions, defined as the indirect site factor (ISF\%) was used to determine the following light categories (Fig. 1):

- Minimal light - under canopy conditions (ISF $<20 \%$ ),

- Low light - at the forest edge, $(20 \%<\mathrm{ISF}<25 \%)$,

- Medium light - in the open with some single trees $(25 \%<\mathrm{ISF}<30 \%)$ and

- High light - without canopy shelter (ISF $>30 \%$ ).

In every light category and every site assimilation response of at least 8 seedlings and same number of dominant sprouts of the same age (10 years), emerging from different stools in coppices were measured.

Colour digital hemispherical photographs were taken during windless days and standard overcast sky conditions $150 \mathrm{~cm}$ above the forest floor and measured seedlings/sprouts, when the solar disk was completely obscured. 15 photos were taken in every light category. The camera was levelled and the fish-eye lens oriented toward magnetic north using a compass prior to each shot. Photographs were taken with a digital Canon Rebel T3 with the fine quality, calibrated fish-eye lens and analysed with WinScanopy software (2010 pro-d). Exposure fitting was done to above canopy conditions prior to shooting on every plot as indicated by Zhang et al. (2005) without noteworthy blooming effects. In the process of hemispherical photograph analysis, a "standard overcast sky" (SOC) model was applied for diffuse light distribution. For the calculation within the vegetation period, the sun's position was specified every 10 min. The solar constant was defined as $1.370 \mathrm{~W} / \mathrm{m}^{2}$,

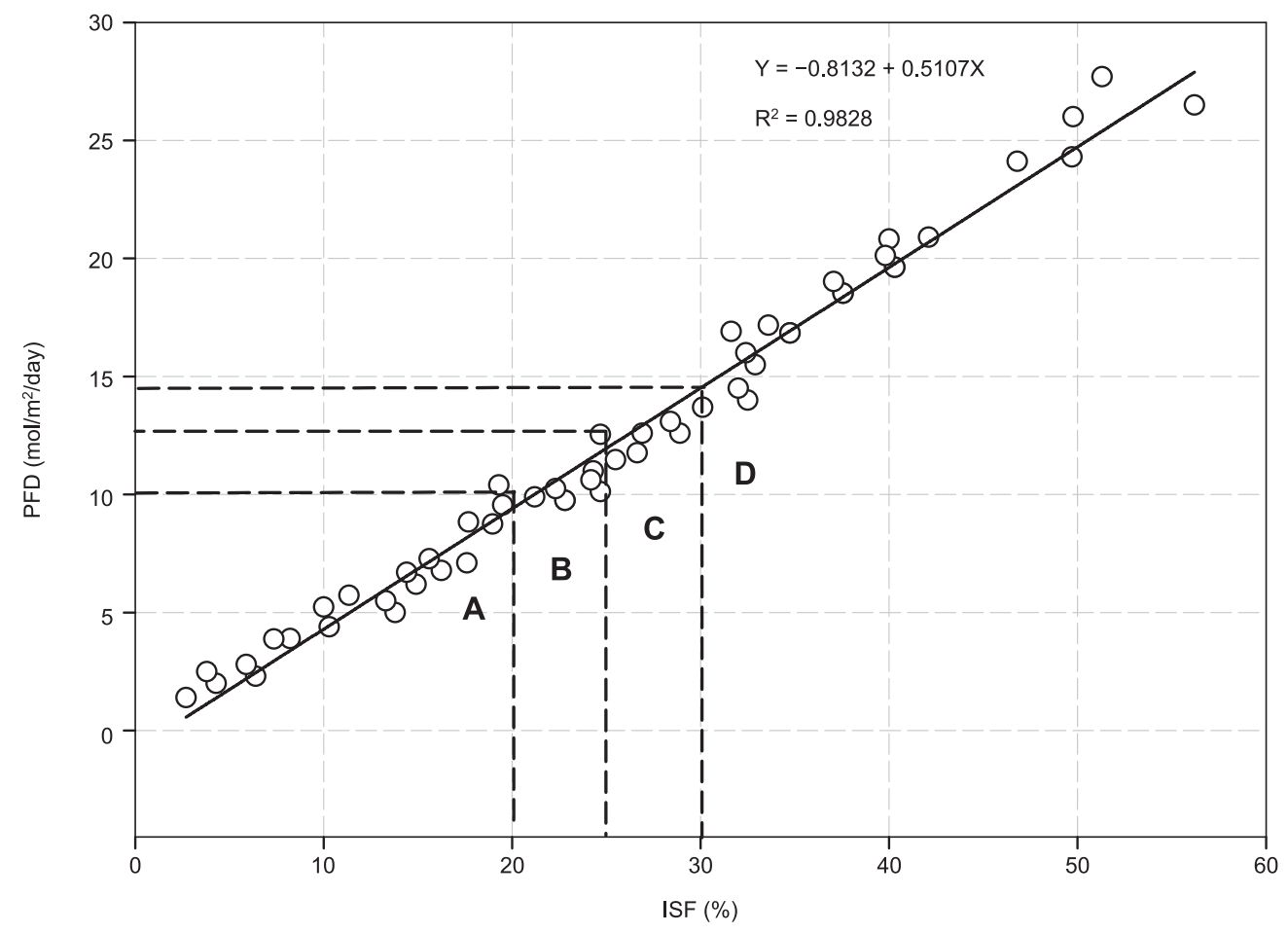

Fig. 1. Light in ISF (\%) corresponding to PFD ( $\mathrm{mol} / \mathrm{m}^{2}$ day) in all observed light categories 
and 0.6 was set for atmospheric transmissivity and 0.15 for the proportion of diffuse radiation compared to calculated direct potential radiation. An automatic thresholding method based on the same colour scheme was applied for the discrimination between sky and canopy elements in all digital photographs.

\section{Assimilation and quantum yield $(\Phi)$}

After determination of comparable light conditions, the assimilation response of seedlings and sprouts in every light category were measured during consecutive growing periods (2012, 2013 and 2014) during same dates (mid-June, end of June, beginning of July) after complete foliage development. Parameters such as $\left(\mathrm{A}_{\max }\right)$ and quantum yield $(\Phi)$ in sprouts and seedlings at different light categories were compared in favourable and dry (2013) conditions (end of July, beginning of August), as described in Čater et al. (2014). Assimilation was measured with Li-6400 portable infra-red gas exchange device.

Light saturation curves were established to compare the ecophysiological response of net assimilation $\left(A_{\max }\right)$. Measurements were performed at a constant temperature of the measurement block $\left(20^{\circ} \mathrm{C}\right)$, a $\mathrm{CO}_{2}$ concentration of $350 \mu \mathrm{mol} / \mathrm{l}$, flow $500 \mu \mathrm{mol} / \mathrm{s}$ and different light intensities: 0, 50, 250, 600, 1200 and $1800 \mu \mathrm{mol} / \mathrm{m}^{2} \mathrm{~s}$. Maximum assimilation $\left(\mathrm{A}_{\max }\right)$ rates were used to compare four groups between different openings of mature canopies. All assimilation values were recorded after they had held constant for 2 min or until the coefficient of variability (CV\%)
Table 1. Average height of seedlings and sprouts $(\mathrm{mm})$ in different light categories

\begin{tabular}{lcccc}
\hline & $\begin{array}{c}\text { Minimum } \\
\text { light }\end{array}$ & $\begin{array}{c}\text { Low } \\
\text { light }\end{array}$ & $\begin{array}{c}\text { Medium } \\
\text { light }\end{array}$ & $\begin{array}{c}\text { High } \\
\text { light }\end{array}$ \\
\hline Standards & $169 \pm 30$ & $1962 \pm 104$ & $2080 \pm 106$ & $2048 \pm 67$ \\
Coppices & $141 \pm 30$ & $1110 \pm 105$ & $1860 \pm 94$ & $2012 \pm 71$ \\
\hline
\end{tabular}

dropped below $5 \%$. The response was measured on at least four sun leaves per tree, located in the upper third of the tree-crown height.

The number of seedling in different light intensity categories changed for standards decreased, while in coppices it increased. With increasing light intensity in both adult standards and coppices numbers of individuals decreased (Fig. 2).

The height of trees of the same age on plots are presented in the following table (Table 1).

Quantum yield, defined as the amount of fixed $\mathrm{CO}_{2}$ per amount of absorbed light quanta (Lambers et al., 1998) were defined for each light category in every forest complex.

\section{Drought conditions}

During measurements, soil moisture was evaluated in the upper soil horizon $(0-10 \mathrm{~cm})$ in three locations at every light treatment by using ThetaProbe ML2x (Delta T Devices, UK).

Drought was considered after five weeks without precipitation at the end of July and the beginning of August 2013 on both locations (http://www. intersucho.cz/en/\#mother), with soil moisture (\%)

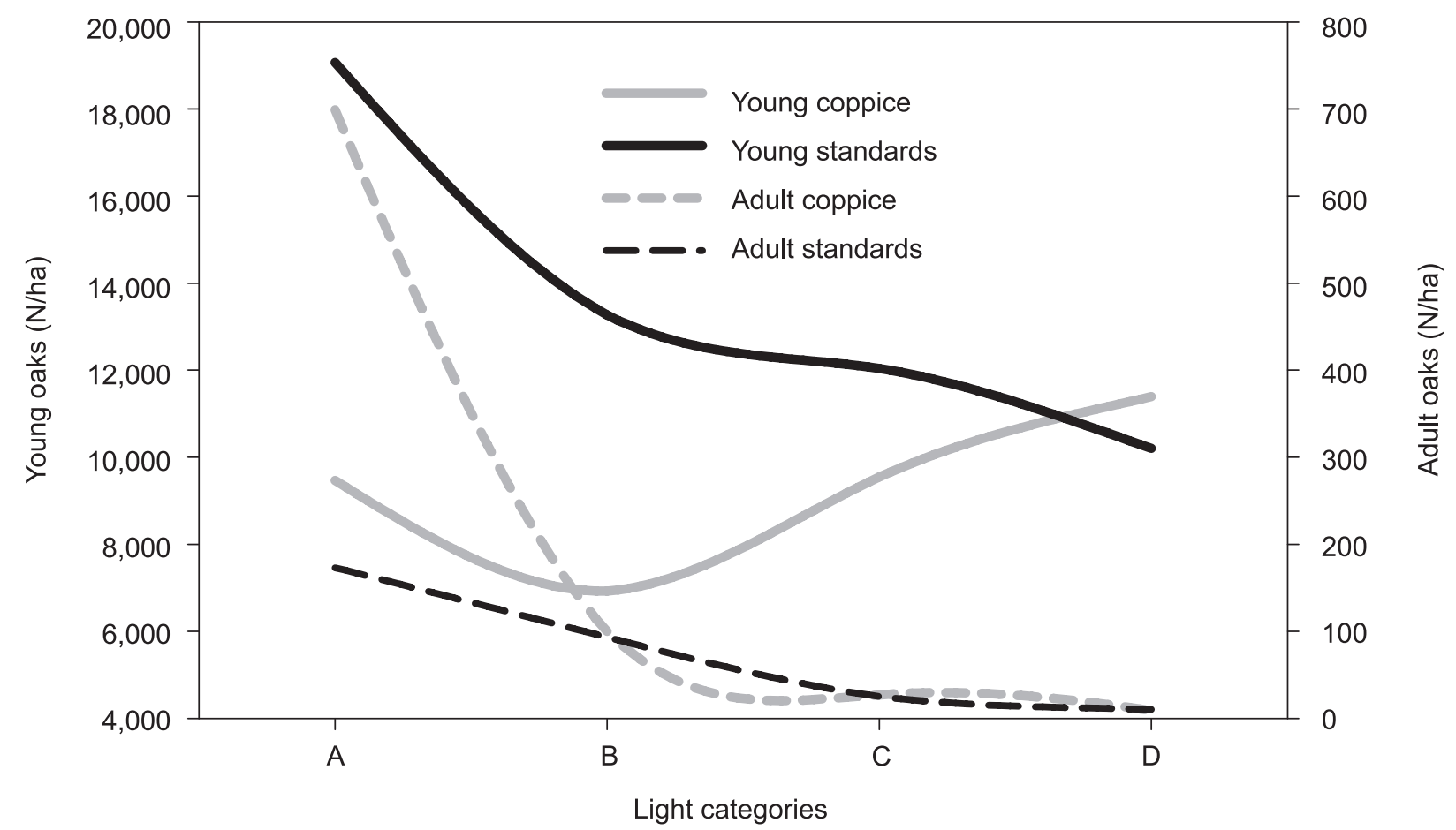

Fig. 2. Number of individuals in every light category. Black lines represent the standards and grey the coppices; straight line represents young trees, while dotted the adult individuals 
significantly dropping from average $38.6 \pm 8.3 \%$ to $10.4 \pm 4.9 \%$ in the upper soil layer $(0-10 \mathrm{~cm})$ $\left(\mathrm{p} \leq 0.000,{ }^{* * *}\right)$.

\section{Data analysis}

One, two and three one way factor analysis of variance (ANOVA) was used for determination of differences in quantum yield between light treatments and between coppices and standards for every year after normality and homogeneity of variances were tested. Also interactions between factors (year of observation, management system, light categories) were evaluated. Significance level was $p<0.05$. Statistical analyses and calculations were performed using StatSoft and Inc., 2004, STATISTICA version 7.0 (www. statsoft.com).

\section{Results}

\section{Maximal photosynthetic response $\left(\mathrm{A}_{\max }\right)$ and quantum yield $(\Phi)$}

Under favourable conditions (2012 and 2014) regarding water limitations no significant differences were observed in $A_{\max }$ in same light categories of sprouts and seedlings.

Differences between light categories in both sites were significant in $2012\left(\mathrm{~F}_{\text {standards }}=3.39 * * *, \mathrm{~F}_{\text {co }}\right.$ pice $=4.72 * * *), 2013\left(\mathrm{~F}_{\text {standards }}=5.84^{*}, \mathrm{~F}_{\text {coppice }}=4.96^{* * *}\right)$ pice $2014\left(\mathrm{~F}_{\text {standards }}=5.12^{* * *}, \mathrm{~F}_{\text {coppice }}=5.17^{* * *}\right)$.

Group with Medium light in the coppiced stands reached the level of maximal assimilation, which was similar to the response of the group in High light in the standards. Category of complete openness in coppices reached highest response in all groups, which was also $9 \%$ higher than response in the same light category of standards (Fig. 3).

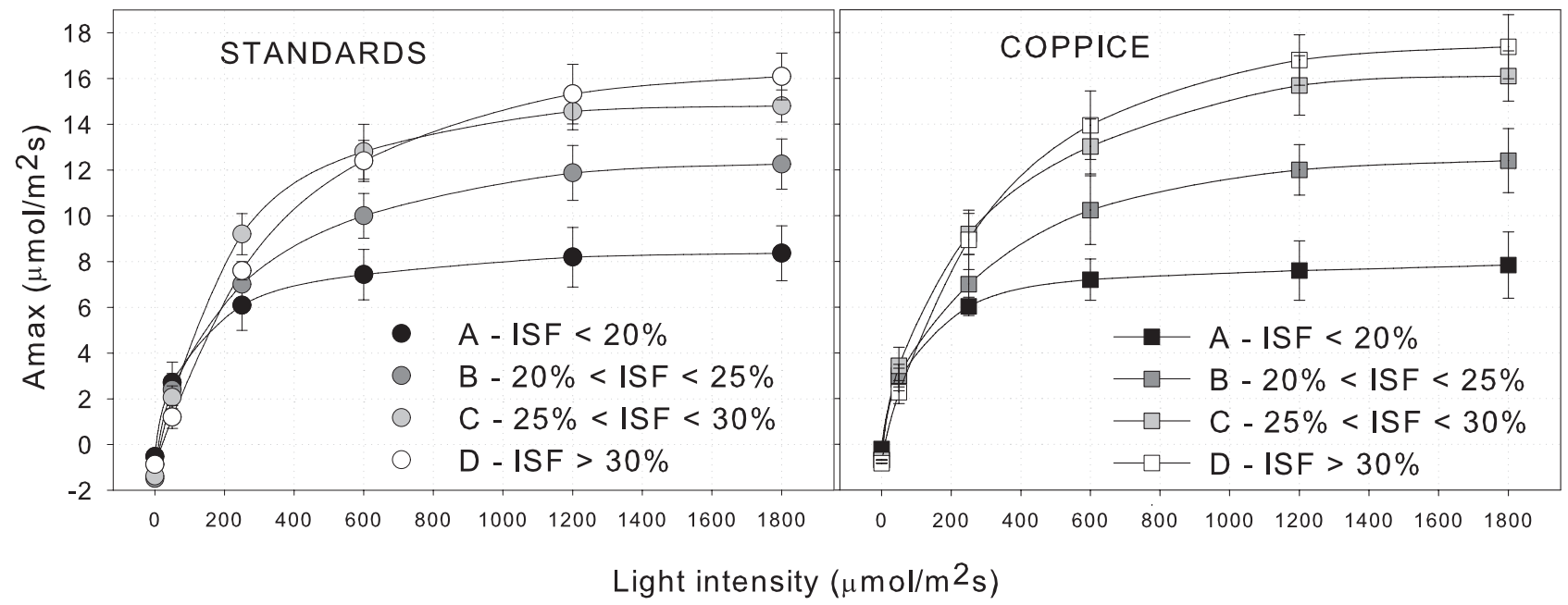

Fig. 3. Maximal assimilation response standard and coppice stands, four light categories. Presented are averages for 2012 for every light category $\left(\mathrm{N}=32, \mathrm{df}_{3,31}\right)$. Bars are standard errors

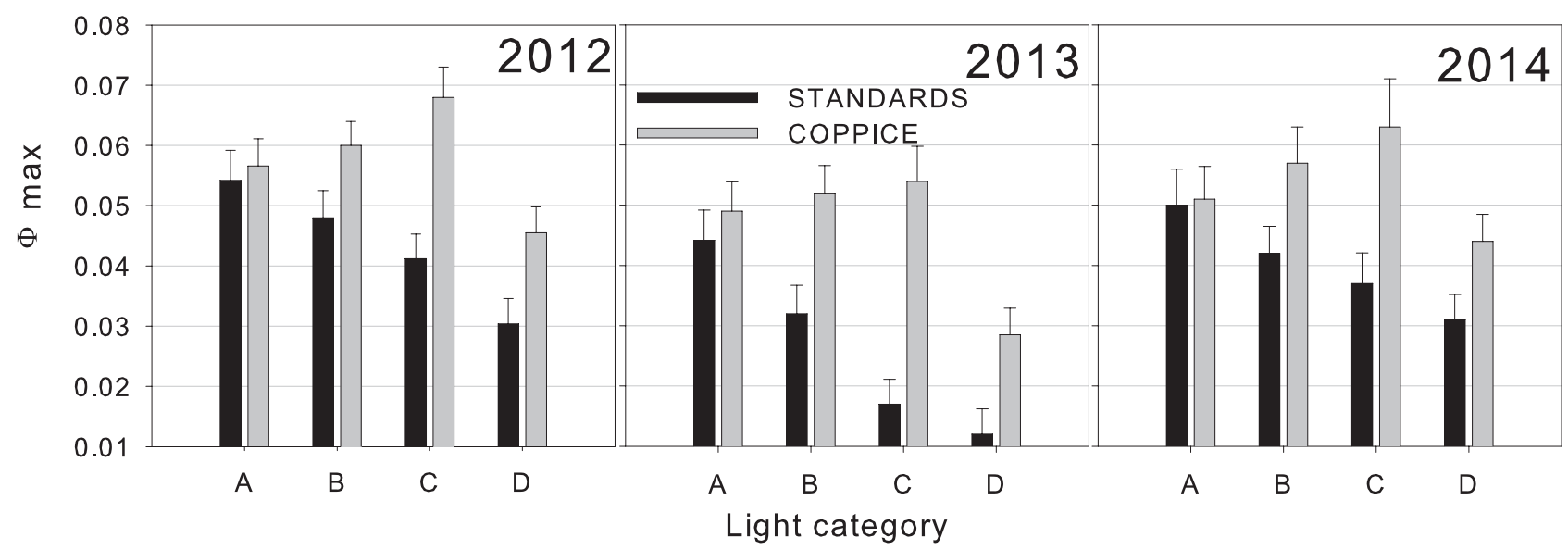

Fig. 4. Maximal quantum yield ( $\Phi$ max) in different light categories and years. Evident drop in response could be noticed in both forest types during 2013 drought conditions. Bars are standard errors 
Table 2. Results of one-, two- and three-way ANOVA (left) and post-hoc analysis for coppice and standards in quantum yield $(\Phi)$ between same light categories (right)

\begin{tabular}{lrcll}
\hline \multicolumn{1}{c}{ Effect } & \multicolumn{1}{c}{$\mathrm{F}$} & $\mathrm{P}$ & \multicolumn{2}{c}{$\begin{array}{c}\text { Standards vs. coppices } \\
\text { 2012 }\end{array}$} \\
\hline Year (1) & 5180,2 & $0,0000^{* * *}$ & Minimum light & $\mathrm{NS}$ \\
System (2) & 17341,5 & $0,0000^{* * *}$ & Low light & $\mathrm{p}=0.000^{* * *}$ \\
Light (3) & 5133,8 & $0,0000^{* * *}$ & Medium light & $\mathrm{p}=0.000^{* * *}$ \\
$1^{*} 2$ & 286,2 & $0,0000^{* * *}$ & High light & $\mathrm{p}=0.000^{* * *}$ \\
$1^{* 3}$ & 252,9 & $0,0000^{* * *}$ & 2013 & \\
$2^{*} 3$ & 2105,1 & $0,0000^{* * *}$ & Minimum light & $\mathrm{NS}$ \\
$1^{*} 2^{*} 3$ & 47,5 & $0,0000^{* * *}$ & Low light & $\mathrm{p}=0.000^{* * *}$ \\
& & & Medium light & $\mathrm{p}=0.000^{* * *}$ \\
& & & High light & $\mathrm{p}=0.000^{* * *}$ \\
& & & 2014 & \\
& & & Minimum light & $\mathrm{NS}$ \\
& & & Low light & $\mathrm{p}=0.000^{* * *}$ \\
& & & Medium light & $\mathrm{p}=0.000^{* * *}$ \\
& & & High light & $\mathrm{p}=0.000^{* * *}$ \\
\hline
\end{tabular}

Quantum yield $(\Phi)$ in all groups of different light intensity was far higher in coppices than in standards. The highest values in standards were recorded in group with lowest light intensity, followed by the groups in Low, Medium and Open light conditions while the highest values in coppices were measured in the group Medium light with almost complete canopy openness, followed by Low light and Minimum light and lowest in the High light category, without mature canopy shelter (Fig. 4).

Analysis confirmed significant differences between years (considered as dry and favourable), between management systems (coppice and standards) and also light categories. All interactions between factors were also highly significant (Table 2).

Quantum yield in category of Minimum light was similar, while in all other categories significantly higher, than in standards.

\section{Drought conditions}

During drought maximal assimilation dropped in all light categories progressively from the complete closure towards open area light conditions. Only the differences in response in the first category (Min. light) were not significant, while in coppices all categories indicated lower values during drought conditions, but (like in Minimum light category, standards) without significance (Fig. 4, 5).

Quantum yield between optimal and drought conditions of the same light categories in standards were all highly significant with exception of Minimum light category where no significant differences were observed $(p=0.0584)$. In coppices the differences between optimal and drought conditions increased by their absolute value from complete closure (Min. light) towards category with smallest canopy cover (Medium light), which also indicated the highest absolute yield also in stressed conditions. Differences in quantum yield were significant only in complete openness (High light), and not in other categories (Fig. 4, 5, Table 2).

\section{Discussion}

The performance of young coppice oaks compared to standards were compared in perspective of dryer climate events under four different light categories. As drought events from the 1990's in central Europe evidently increase (Trnka et al., 2011), the rise of temperatures is reported to be more influential than decrease in precipitation (Brázdil et al., 2013; Čater, 2015). In regions prone to drought, heat exposure in canopy gaps and an increase in temperature at ground level are detrimental to plant germination. Management systems, such as coppicing, have been adapted to such climate (Coppini \& Hermanin, 2007).

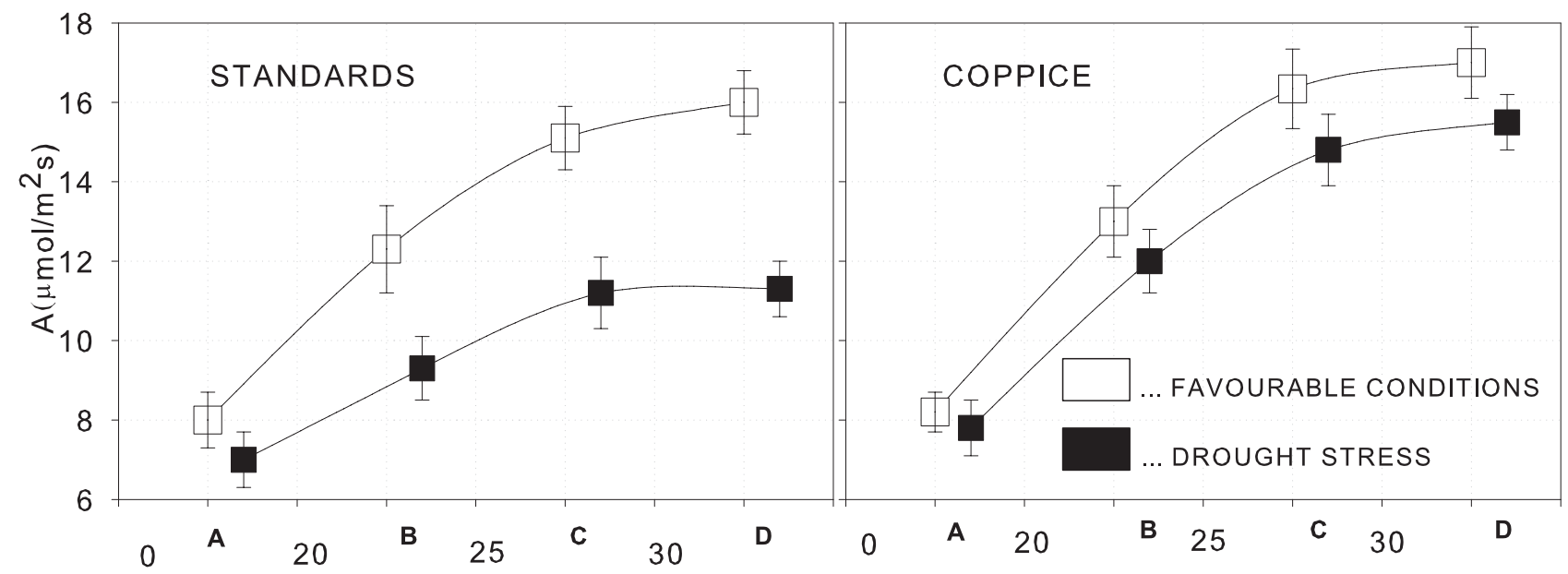

Fig. 5. Maximal assimilation response standard and coppice stand conditions, all light categories during favourable (empty characters) and drought conditions (black characters). Bars are standard errors 
Increased soil water content after coppicing were reported by Salisbury (1924) and Cummings and Cook (1992) in Tilia cordata and Corylus avellana forest, managed in the past as a coppice-with-standards. Similar results were reported by Cotillas et al. (2009) where was soil water content in dry years significantly higher under recently coppiced plots (cut 3-5 years prior to the study) compared with older plots (cut 9-11 years before). Surface soil water content depleted faster under higher densities of stools (2000 stools/ha) before canopy closure.

In our study during optimal conditions, the maximal assimilation of young standard sessile oaks increased progressively with increasing light; values were always higher in corresponding categories of coppices, indicating their advantage over standards.

The maximal assimilation rates indicated similar distribution in first two light categories under shelter conditions between coppices and standards, while in Open light a clear difference was observed between both forest types.

The maximal quantum yield in coppices showed just the opposite pattern according to the light categories than standards; in 2012 they both started with comparable responses in the dark, in the category with most of the canopy coverage (Min. light, $\Phi_{\text {coppice }}=$ $\left.0.0564, \Phi_{\text {standards }}=0.0542\right)$ and gradually decreased with increasing light (Low, Medium and Open light, $\Phi_{\text {standards }}=0.0304$ ), while in coppices it increased with light and reached its maximum in the category of 25 $30 \%$ ISF (Medium light, $\Phi_{\text {coppice }}=0.0677$ ), showing completely different adaptation with increasing light.

During drought (2013) the absolute value between light categories in standards decreased significantly, but the relative pattern remained the same. In the coppices the drop in efficiency of all categories was evident, but not as significantly as in standards. Most pronounced was the difference in the light category of Medium light, corresponding to $15 \mathrm{~mol} / \mathrm{m}^{2}$ day radiation, where $\Phi$ in standards dropped below 0.018 and only to 0.0542 in coppices.

Recovery rates in 2014 were in all categories lower than values from 2012. It is our belief that coppices adapt to available resources in root systems, as also the number of seedlings in coppices followed the same pattern (Fig. 2).

Coppices have expressed potential against standard seedlings in quantum yield, especially under drought stress, proved by our experiment. Several studies showed better performance of sprouts in earliest stages (Lloret et al., 2004). Drake et al. (2009) confirmed that coppice and standards experience different water availability because of contrast in the spatial distribution of roots and differences in amount of below-ground biomass. Accordingly, water-use efficiency can be greater for coppice compared to seedlings in early development stages, as there is an excess of water and nutrients relative to plant's requirements, so photosynthetic apparatus is not limited by resource availability (Drake et al., 2012). However, it is not certain if the pronounced advantage would persist also during further, older development phases, or is it accumulated and evident only during the first competition phase and then gradually wears out.

Several studies conducted on traditional coppice systems provide an insight into the changes in structure and function of over-mature coppice (Corcuera et al., 2006). Age dependent responses to climatic stress, which altered the wood anatomy and survival of Pyrenean oak coppiced trees in the Mediterranean basin (Corcuera et al., 2006) showed, that over-mature coppice was more vulnerable to climatic stress and xylem cavitation owing to the lower proportion of latewood vessels, known to be less vulnerable to embolism.

Drought susceptibility increased also in coppices of Populus deltoides, grown under elevated $\mathrm{CO}_{2}$ conditions, which were also more susceptible to xylem cavitation, displaying lower wood densities coupled with high stomatal densities (Bobich et al., 2010).

Direct impacts on tree physiology (changes occurring shortly after cutting) have been detected in in situ and ex situ experiments on coppice. An experimental study, which simulated a $15 \%$ reduction in rainfall in thinned and unmanaged Mediterranean mixed coppice of Q. ilex and Quercus cerrioides in Spain, found differences on species response to drought (Cotillas et al., 2009). Thinning essentially involved the reintroduction of the coppice selection system, which was historically common in the area. Only the deciduous $Q$. cerrioides suffered decreases in relative height growth rate with reduced rainfall.

Even if the recruitment of new individuals from seeds is from the productive point not questionable, their importance increases when the potential decay or abandonment of these forests and their genetic diversity is under question. Some authors (Floret et al., 1992; Ducrey, 1992) state, that perseverance of individuals by the sprouting mechanism might cause the eventual genetic senescence and decrease in productivity of coppices. As the coppices have been applied on the sites with harsh site conditions, especially where drought represented the limiting survival aspect, several researchers (Ranger \& Bonneau, 1986; Ranger \& Nys, 1996) linked coppicing with the risks of the soil environment degradation, reduction in soil fertility and production potential with increased use of nutrients, loss of fertility and loss of organic matter. The rate of potential degradation depends also on the mineral strength of the site and duration of coppicing, with long-term reduction of soil fertility and thus the production and stability of the forest ecosystem being the consequence (Kupec et al., 2015). However, the beneficial effects of restoration coppicing are not guaranteed. When reintroduced, 
coppicing can pose threats to biodiversity by enhancing the spread of ruderal species of native origin and even the invasion of aliens (Vild et al., 2013).

\section{Conclusions}

In presented study performance of different light categories of standards and coppices sessile oaks were observed. The performance of coppices overpassed the maximal assimilation in open light categories during both favourable and drought conditions, while maximal quantum yield was highest in the category of medium light for coppices and for standards in category of minimal light. During drought performance of coppices was better than in standards, showing only slight decrease in quantum yield compared to favourable year, due to established root system.

Our first hypothesis that same light categories between the two systems would show no differences proved wrong, as differences between both systems were highly different.

Also our second hypothesis that no differences would be confirmed between same light categories of different systems in drought was not confirmed, as differences were highly significant.

Our study confirmed advantage of coppiced sessile oaks over standards which may be beneficial on extreme sites and reduced water availability, where continuous forest cover is required. However, such conclusions should be considered with reservation, as we believe that advantage might decrease in time. Further comparisons would be required to compare responses in time and define, when such response abilities of both systems would become equal.

\section{Acknowledgement}

Presented research was financially supported by Mendel University in Brno, Grant IGA 55/2014, project "Coppice" No. CZ.1.07/2.3.00/20.0267 and program research group Forest Biology, Ecology and Technology P4-0107 at the Slovenian Forestry Institute.

\section{References}

Actual drought situation of Czech Republic. http:// www.intersucho.cz/en/\#mother, Accessed for the year 2013.

Allen CD, Macalady AK, Chenchouni H, Bachelet D, McDowell N, Vennetier M, Kitzberger T, Rigling A, breshears DD, Hogg EH, Gonzalez P, Fensham $\mathrm{R}$, Zhang Z, castro J, Demidova N, Lim J-H, Allard G, Running SW, Semerci A \& Cobb N (2010) A global overview of drought and heat-induced tree mortality reveals emerging climate change risks for forests. Forest Ecology and Management 259: 660-684.

Aranda I, Gil L \& Pardos J (1996) Seasonal water relations of three broadleaved species (Fagus sylvatica L., Quercus petraea (Mattuschka) Liebl. and Quercus pyrenaica Willd.) in a mixed stand in the centre of the Iberian Peninsula. Forest Ecology and Management 84: 219-229.

Arend M, Kuster T, Günthardt-Goerg MS \& Dobbertin M (2011) Provenance-specific growth responses to drought and air warming in three European oak species (Quercus robur, Q. petraea and Q. pubescens). Tree Physiology 31: 287-297.

Bobich EG, Barron-Gafford GA, Rascher KG \& Murthy $R$ (2010) Effects of drought and changes in vapour pressure deficit on water relations of Populus deltoides growing in ambient and elevated CO2. Tree Physiology 30: 866-875.

Brázdil R, Dobrovolný P, Trnka M, Kotyza O, Řezníčková L, Valášek H, Zahradníček P \& Štěpánek P (2013) Droughts in the Czech lands, 1090-2012 AD. Climate of the past 9, no. 4, pp. 1985-2002.

Bréda N, Cochard H, Dreyer E \& Granier A (1993) Field comparison of transpiration, stomatal conductance and vulnerability to cavitation of Quercus petraea and Quercus robur under water stress. Annals of Forest Science 50: 571-582.

Buckley GP (1992) Ecology and management of coppice woodlands. Springer Science \& Business Media, London.

Čater M (2015) A 20-year overview of Quercus robur L. mortality and crown conditions in Slovenia. Forests 6: 581-593.

Čater M, Diaci J \& Roženbergar D (2014) Gap size and position influence variable response of Fagus sylvatica L. and Abies alba Mill. Forest Ecology and Management 325: 128-135.

Čater M, Schmid I \& Kazda M (2012) Instantaneous and potential radiation effect on underplanted European beech below Norway spruce canopy. European Journal of Forest Research 132: 23-32.

CHMI (2014) Czech Hydrometeorological Institute. http://www.chmi.cz.

Coppini M \& Hermanin L (2007) Restoration of selective beech coppices: a case study in the Apennines (Italy). Forest Ecology and Management: 249: 18-27.

Corcuera L, Camarero JJ, Sisó S \& Gil-Pelegrín E (2006) Radial-growth and wood-anatomical changes in overaged Quercus pyrenaica coppice stands: functional responses in a new Mediterranean landscape. Trees 20: 91-98.

Cotillas M, Sabate S, Gracia C \& Espelta JM (2009) Growth response of mixed Mediterranean oak coppices to rainfall reduction: could selective thinning have any influence on it? Forest Ecology and Management 258: 1677-1683. 
Cummings I \& Cook H (1992) Soil-water relations in an ancient coppice woodland: Ecology and management of coppice woodlands. Springer, Netherlands, pp. 52-75.

Dickson RE \& Tomlinson PT (1996) Oak growth, development and carbon metabolism in response to water stress. Annales des Sciences Forestieres 53: 181-196.

Drake PL, Mendham DS, White DA \& Ogden GN (2009) A comparison of growth, photosynthetic capacity and water stress in Eucalyptus globulus coppice regrowth and seedlings during early development. Tree Physiology 29: 663-674.

Drake PL, Mendham DS, White DA, Ogden GN \& Dell B (2012) Water use and water-use efficiency of coppice and seedling Eucalyptus globulus Labill.: a comparison of stand-scale water balance components. Plant and Soil 350: 221-235.

Ducrey M (1992) Quelle sylviculture et quel avenir pour les taillis de chêne vert (Quercus ilex L.) de la région méditerranéenne française. Revue Forestiere Française 44: 12-34.

Floret C, Galan MJ, Le Floc'h E \& Romane F (1992) Dynamics of holm-oak (Quercus ilex) coppices after clearcutting in southern France. Flora and life cycles changes. Vegetatio 100: 97-105.

Honnay O, Verheyen K, Bossuyt B \& Hermy M (2004) Forest biodiversity: lessons from history for conservation. CABI Publishing, Wallingford.

IPCC. Climate Change (2001) The scientific basis. Intergovernmental panel on climate change. Cambridge University Press, Cambridge.

Jump AS, Cavin L \& Hunter PD (2010) Monitoring and managing responses to climate change at the retreating range edge of forest trees. Journal of Environmental Monitoring 12: 1791-1798.

Kadavý J, Kneifl M \& Knott R (2011) Biodiversity and target management of endangered and protected species in coppices and coppices with standards included in system of NATURA 2000: methodology of establishment of experimental research plots in the conversion to coppice and coppice-with-standards and their description. Mendel University in Brno, Brno.

Kupec P, Kučera A, Kadavý J \& Kneifl M (2015) Contribution to a discussion on the influence of coppicing on soil environment. Journal of Forest Science 61: 216-224.

Lambers H, Chapin III FS \& Pons TL (1998) Plant physiological ecology. Springer, New York.

Leuzinger S, Zotz G, Asshoff R \& Körner C (2005) Responses of deciduous forest trees to severe drought in Central Europe. Tree Physiology 25: 641-650.

Lindner M, Maroschek M, Netherer S, Kremer A, Barbati A, Garcia-Gonzalo J, Seidl R, Delzon S, Corona P, Kolström, Lexer MJ \& Marchetti M (2010)
Climate change impacts, adaptive capacity, and vulnerability of European forest ecosystems. Forest Ecology and Management 259: 698-709.

Lloret F, Penuelas J \& Ogaya R (2004) Establishment of co-existing mediterranean tree species under a varying soil moisture regime. Journal of Vegetation Science 15: 237-244.

McKenney DW, Yemshanov D, Fraleigh S, Allen D \& Preto F (2011) An economic assessment of the use of short-rotation coppice woody biomass to heat greenhouses in southern Canada. Biomass \& Bioenergy 35: 374-384.

Milad M, Schaich H, Bürgi M \& Konold W (2011) Climate change and nature conservation in Central European forests: A review of consequences, concepts and challenges. Forest Ecology and Management 261: 829-843.

Millar CI, Stephenson NL \& Stephens SL (2007) Climate change and forests of the future: managing in the face of uncertainty. Ecological applications 17: 2145-2151.

Müllerová J, Hédl R \& Szabó P (2015) Coppice abandonment and its implications for species diversity in forest vegetation. Forest Ecology and Management 343: 88-100.

Pérez-Ramos IM, Ourcival JM, Limousin JM \& Rambal S (2010) Mast seeding under increasing drought: results from a long-term data set and from a rainfall exclusion experiment. Ecology 91: 3057-3068.

Peterken G (1993) Woodland conservation and management. 2nd ed. Chapman \& Hall, London.

Peterken GF (1996) Natural woodland: ecology and conservation in northern temperate regions. Cambridge University Press, Cambridge.

Rackham O (2008) Ancient woodlands: modern threats. New Phytologist 180: 571-586.

Ranger J \& Bonneau M (1986) Effets previsibles de 1 'intensi-fication de la production et des recoltes sur la fertilite des sols de forêt. Les effets de la sylviculture. Revue forestière française 38: 105-123.

Ranger J \& Nys C (1996) Biomass and nutrient content of extensively and intensively managed coppice stands. Forestry 69: 91-110.

Salisbury EJ (1924) The effects of coppicing as illustrated by the woods of Herfordshire. Transactions of the Hertfordshire Natural History Society and Field Club 18: 1-21.

Silva DE, Mazzella PR, Legay M, Corcket E \& Dupouey JL (2012) Does natural regeneration determine the limit of European beech distribution under climatic stress? Forest Ecology and Management 266: 263-272.

Sjölund MJ \& Jump AS (2013) The benefits and hazards of exploiting vegetative regeneration for forest conservation management in a warming world. Forestry 86: 503-513. 
StatSoft Inc. (2004) Statistica 7.0, Statistical software, StatSoft. http://www.statsoft.com.

Thomas FM \& Gausling T (2000) Morphological and physiological responses of oak seedlings (Quercus petraea and $Q$. robur) to moderate drought. Annals of Forest Science 57: 325-333.

Trnka M, Brázdil R, Dubrovský M, Semerádová D, Štěpánek P, Dobrovolný P, Možný M, Eitzinger J, Málek J, Formayer H, Balek J \& Žalud Z (2011) A 200-year climate record in Central Europe: implications for agriculture. Agronomy for Sustainable Development 31: 631-641.

Vild O, Roleček J, Hédl R, Kopecký M \& Utinek D (2013) Experimental restoration of coppice-with-standards: Response of understorey vegetation from the conservation perspective. Forest Ecology and Management 310: 234-241.
Zhang Y, Chen JM \& Miller JR (2005) Determining digital hemispherical photograph exposure for leaf area index estimation. Agricultural and Forest Meteorology 133: 166-181.

Zhu WZ, Xiang JS, Wang SG \& Li MH (2012) Resprouting ability and mobile carbohydrate reserves in an oak shrubland decline with increasing elevation on the eastern edge of the Qinghai-Tibet Plateau. Forest Ecology and Management 278: 118-126.

Zweifel R, Rigling A \& Dobbertin M (2009) Species-specific stomatal response of trees to drought-a link to vegetation dynamics? Journal of Vegetation Science 20: 442-454. 